\title{
Optimization of process variables of continuous type ohmic heating for milk pasteurization
}

\author{
Anupam Amitabh, S K Jain and Vishal Kumar
}

Received: 20 October 2018 / Accepted: 15 January 2019 / Published online: 18 April 2019

(C) Indian Dairy Association (India) 2019

\begin{abstract}
Experiments were conducted according to Box Behnken Design for optimization of ohmic heating $(\mathrm{OH})$ for pasteurization of milk (fat content: 3 per cent, 4.5 per cent, and 6 per cent) in a continuous type ohmic heating unit. The three $\mathrm{OH}$ process variables were fat content of milk, applied voltage and inlet temperature of milk. Optimum conditions obtained by numerical optimization were fat content of 5 per cent, applied voltage $30 \mathrm{~V}$ and feeding temperature of $40^{\circ} \mathrm{C}$ in order to obtain optimized yield as final temperature $(\mathrm{T})-72{ }^{\circ} \mathrm{C}$; and specific performance coefficient (SPC) - 79.89 with desirability of 0.753 .
\end{abstract}

Keywords: Box Behnken, Milk, Ohmic heating, Pasteurization, Response Surface Methodology, SPC

\section{Introduction}

Ohmic heating is an alternative and advanced thermal processing method in which heat is internally generated by the passage of alternating electrical current (AC) through the food system that serves as an electrical resistance. The success of ohmic heating depends on the rate of heat generation in the system, electrical field strength, the electrical conductivity of the food, residence

\footnotetext{
Anupam Amitabh $(\bowtie)$

Department of Processing and Food Engineering, Dr. RPCAU, Pusa, India

E-mail: anupam.amitabh2010@gmail.com

S K Jain

Department of Processing and Food Engineering, MPUAT, Udaipur, India

Vishal Kumar

Department of Processing and Food Engineering, Dr. RPCAU, Pusa, India
}

time and the method by which the food flows through the system. $\mathrm{OH}$ seems to allow obtaining value added products of a superior quality without compromising food safety (Tucker 2004; Pereira et al. 2007). Because the energy is almost entirely dissipated within the heated material, there is no need to heat intervening heat exchange walls - thus the process has close to 100per cent energy transfer efficiency (Salengke 2010). Novel thermal and non - thermal processing technologies based on physical techniques for food preservation have the potential to address the demands of the consumer and deliver high quality processed foods with an extended shelf life that are additive free and have not been subjected to extensive heat treatment.

In recent decades, technologies utilizing electrical energy directly into food processing have attracted renewed interest in the food industry. Some of those are now being used on a commercial scale for processing of a broad range of food products. Milk is heated to enhance its shelf life. There are various processes associated with heating of milk such as pasteurization, sterilisation, etc. Pasteurization is the heating of every particle of milk or milk product to a specific temperature for a specified period of time without allowing recontamination of that milk or milk product during the heat treatment process. Generally during pasteurization milk is heated to $71.7^{\circ} \mathrm{C}\left(161^{\circ} \mathrm{F}\right)$ for $15-20$ seconds. Sterilization refers to heating of milk to $120^{\circ} \mathrm{C}$ for a few minutes or to just over $100^{\circ} \mathrm{C}$ for 20 to 30 minutes and aseptically sealed in a narrow necked bottle with a crown cork. Hence, the main objective of this study was to optimize the process variables of a developed continuous type ohmic heating for milk pasteurization.

\section{Materials and methods}

\section{Experimental set up of the developed ohmic unit}

The pasteurization of milk was carried in a continuous type ohmic heating unit which consists of an electrical control panel, storage tanks and two ohmic heating stainless steel (SS 304) co- axial pipes with outer diameter of $3.1 \mathrm{~cm}$ and inner diameter of $2.1 \mathrm{~cm}$ with a gap of $0.8 \mathrm{~cm}$ in between them. The aim of the first unit was to increase the temperature of liquid to required temperature while the second unit was meant for precision heating as per the required temperature of pasteurization of liquid foods. For 
precision heating, at the outlet of the second unit, a flow diversion valve was fitted to divert the under processed liquid to the storage tank for reprocessing. The concentric pipe was plugged with a Teflon material to make it leak proof and insulation of glass wool was provided to the pipes. The unit also comprised of support frames, temperature recorder or sensor, thermocouples and digital FDV meter (Fig. 1) (Amitabh, 2017). Voltage was adjusted using auto transformer $(230 \mathrm{~V}, 15 \mathrm{Amp})$. The specified voltage was applied across the sample and temperature variations were measured at every regular interval.

\section{Ohmic heating of liquid food}

Three different raw milk containing fat content 3 per cent, 4.5 per cent and 6 per cent were procured from local market of Udaipur. Before undergoing ohmic heating the milk was stored at refrigeration conditions at $4 \pm 1{ }^{\circ} \mathrm{C}$ temperature. For the continuous ohmic heating treatment, 25 liters of milk was placed in the storage tank. The sample was fed to the first ohmic heating chamber by a gravity flow and the ûow rate was controlled using control valves at the inlet and outlet of the ohmic heating unit. Experiments on milk pasteurization were conducted as per the Box-Behnken design.

\section{Experimental design}

Box-Behnken Design and Response Surface methodology were used to optimize ohmic heating process variables for pasteurization of milk. The experimental design was made with following independent and dependent ohmic heat parameters/ variables with respective values:

\section{Independent Variables}

i.Fat content of milk : 3 per cent, 4.5 per cent, 6 per cent

ii. Potential difference (V) : 30, 40, 50

iii. Inlet temperature of milk (ÚC) : 30, 35, 40

\section{Dependent Variables}

1. Final temperature of liquid at outlet.

2. Ohmic heating performance coefficient(SPC)

3. Capacity (lph)

\section{Analysis of data}

The data were analyzed using Design Expert 8 (Stat-Ease, Minneapolis, MN, USA) to obtain a quadratic mathematical model. RSM has been used with Box Behnken Design to optimize ohmic heating process variables. Regression analysis and analysis of variance (ANOVA) were conducted for fitting the model represented by Eq. (1) to the experimental data and to examine the statistical significance of the model terms.

$Y=a_{o}+\sum_{i=1}^{n=3} a_{i} x_{j}+\sum_{i=1}^{n=3} \sum_{j=1}^{n=3} a_{i j} x_{i} x_{j}$

where: $Y, a_{0}, X_{i}$ and $X_{j}, a_{i}$, and $a_{i j}$ are the predicted responses of the dependent variable, second-order reaction constant, independent variables, linear regression coefficient, and regression coefficient of interactions between two independent variables, respectively.

The adequacies of the models were determined using model analysis, lack-of-fit test, and $\mathrm{R}^{2}$ (coefficient of determination) analysis as outlined by Lee et al., 2000; Weng et al, 2001 and Sastry and Barach, 2000. The lack-of-fit is a measure of the failure of a model to represent data in the experimental domain at which points were not included in the regression and variations in the models cannot be accounted by random error (Montgomery, 1984). If there is a significant lack of fit as indicated by a low probability value, the response predictor is discarded. The $\mathrm{R}^{2}$ (coefficient of determination) is defined as the ratio of the explained variation to the total variation and is a measure of the degree of fit (Haber and Runyon, 1977). Coefficient of variation (CV) indicates the relative dispersion of the experimental points from the model prediction. Response surfaces were generated and numerical optimization was also performed by Design Expert software.

\section{Optimization Technique}

Numerical optimization technique of Design Expert was used for simultaneous optimization of the multiple responses. The desired goals for each factor and response were chosen. The possible goals were maximize, minimize, target, within range, none (for responses only). All the independents factors were kept within the experimental range while the responses were either maximized or minimized. In order to search a solution for multiple responses, the goals were combined into an overall composite function, $\mathrm{D}(\mathrm{x})$, called the desirability function (Myers and Montgomery, 2002) which is defined as

$\mathrm{D}(\mathrm{x})=\left[\mathrm{d}_{1} \mathrm{Xd}_{2} \mathrm{Xd}_{3} \mathrm{X} \ldots \ldots \mathrm{d}_{\mathrm{n}}\right]^{1 / \mathrm{n}} \quad \ldots \ldots \ldots \ldots \ldots \ldots$

where $d_{1}, d_{2}, \ldots, d_{n}$ are responses and $n$ is the total number of responses in the measure. The function $\mathrm{D}(\mathrm{x})$ reflects the desirable ranges for each response (di). Desirability is an objective function that ranges from zero (least desirable) outside of the limits to one (most desirable) at the goal. The numerical optimization finds a point that maximizes the desirability function. The goal-seeking begins at a random starting point and proceeds up the steepest slope to a maximum. There may be two or more maximums because of curvature in the response surfaces and 
Fig.1 Schematic diagram of continuous type ohmic heating unit

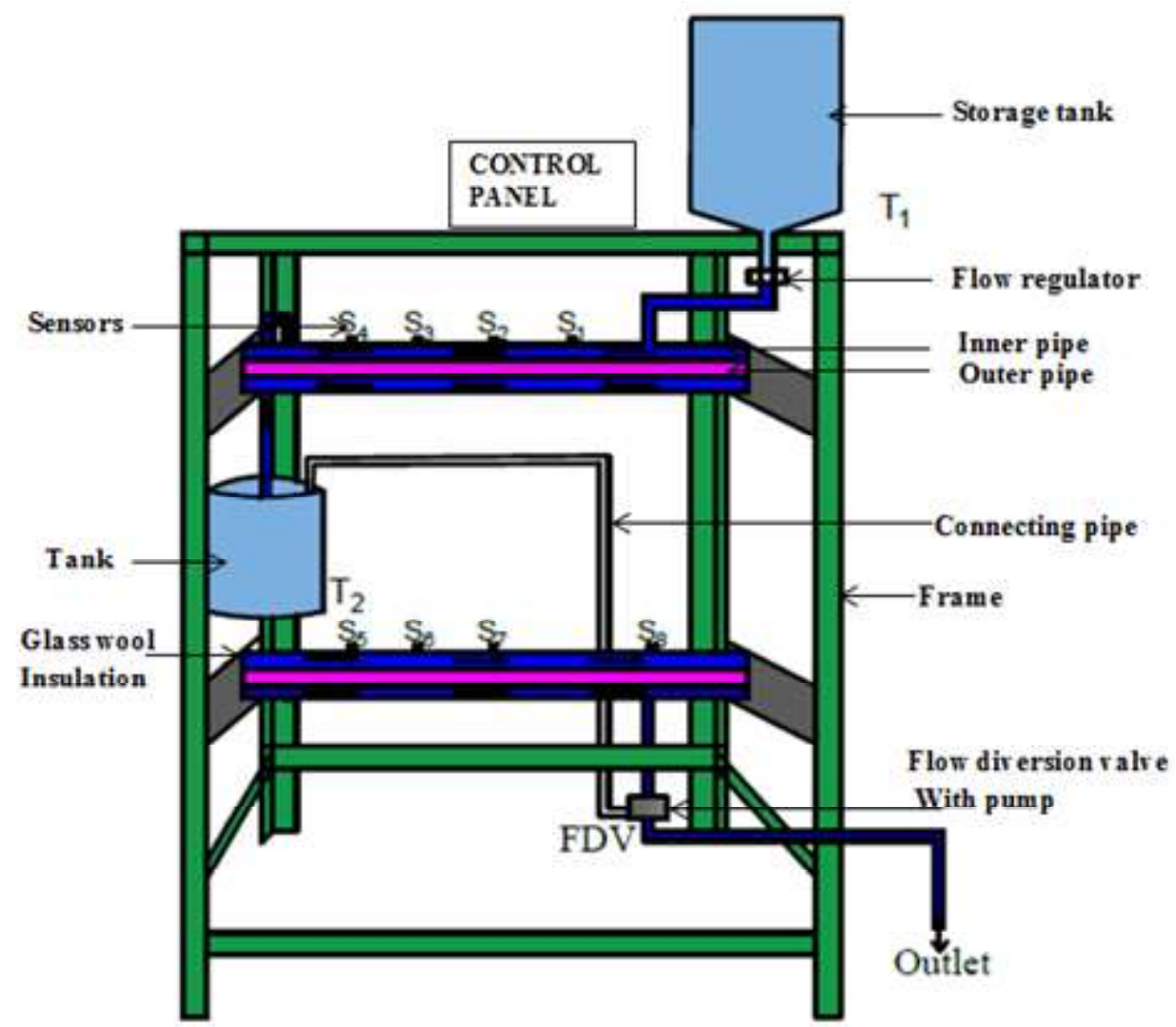

their combination into the desirability function. By starting from several points in the design space, chances improve for finding the best local maximum.

\section{Measurement of dependent variable}

\section{Determination of Final temperature}

The final temperature of milk was measured at the outlet with the help of thermocouple placed at different sections of the ohmic unit as shown in figure. The final temperature of processed milk after passing through flow diversion valve was measured as the final outlet temperature of milk.

\section{System performance coefficient (SPC)}

The performance of the ohmic heating unit was evaluated by system performance coefficient (SPC) which is ratio of energy converted to useful work to energy provided to the system (Nargesi et al., 2011).

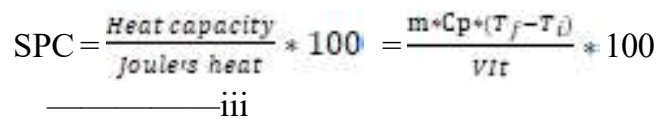

Where,
$\mathrm{SPC}$ is system Performance Coefficient

$\mathrm{m}$ is mass $(\mathrm{kg})$

$\mathrm{C}_{\mathrm{p}}$ is specific heat capacity $\left(\mathrm{J} / \mathrm{kg}^{0} \mathrm{C}\right)$

$T_{f}$ is final temperature $\left({ }^{0} \mathrm{C}\right)$

$T_{i}$ is initial temperature $\left({ }^{0} \mathrm{C}\right)$

$\mathrm{V}$ is electric potential (V)

\section{Capacity}

The capacity of the unit was measured by dividing the volume of milk collected in tank at outlet to time taken for attaining the pasteurization temperature.

\section{Results and discussion}

The estimated regression coefficients of the quadratic polynomial models (Eq. (1)) for various responses and the corresponding $\mathrm{R}^{2}$ and $\mathrm{CV}$ values are given in Table 3 . Analysis of variance indicated that the models are highly significant at pd" 0.05 for all the responses (Table 4 and Table 5). The lack of fit did not result in a significant F-value in case of temperature (T), SPC (per cent) and capacity $(\mathrm{lph})$ indicating that the models are sufficiently accurate 
for predicting these responses supported by low value of PRESS and CV. Despite the lack of fit is significant in the case of overall acceptability $\left(\mathrm{O}_{\mathrm{A}}\right)$, acceptable PRESS, CV (less than 10per cent), $\mathrm{R}^{2}$ values indicates that the model is sufficient to predict the response.

As a general rule, the coefficient of variation should not be greater than 10per cent. In this case, the coefficients of variation for all the responses were less than 7 per cent (Table 3 ).

In this case, the coefficients of variation for all the responses were less than 7 per cent (Table 3). The C.V. 0.10, 4.29 and 6.69 per cent for final temperature, SPC and capacity. The goodness of fit of the model is checked by the determination coefficient $\left(\mathrm{R}^{2}\right)$. The coefficient of determination $\left(\mathrm{R}^{2}\right)$ was $0.98,0.9819$ and 0.8874 for T, SPC and capacity respectively.

\section{Effect on temperature}

The second order polynomial multiple regression equation for explaining the effect of variation in ohmic process parameters $\mathrm{A}$, $\mathrm{B}$ and $\mathrm{C}$ on $\mathrm{T}$ is as follows:
Final Temperature $(\mathrm{T})=72.82+0.65 \mathrm{~A}+0.28 \mathrm{~B}+0.100 \mathrm{C}+0.12 \mathrm{AB}-$ $0.025 \mathrm{~A} \quad \mathrm{C}+0.025 \mathrm{~B} \quad \mathrm{C}+0.077 \mathrm{~A}^{2}+0.077 \quad \mathrm{~B}^{2}-0.072 \mathrm{C}^{2}$ $\left(\mathrm{R}^{2}=0.9910\right.$

The relative magnitude of coefficients indicates the positive contribution of all process variables except interactive effect of $\mathrm{A}$ and $\mathrm{C}$ and the $\mathrm{C}$ squared effects. The estimated regression coefficients of the quadratic polynomial models (Eq. 4.1) for various responses and the corresponding $\mathrm{R}^{2}$ and $\mathrm{CV}$ values are given in Table 3 . The models are highly significant for all the responses. The lack of fit did not result in a significant value in case of $\mathrm{A}, \mathrm{B}$ and $\mathrm{C}$ indicating that the models are sufficiently accurate for predicting these responses supported by low value of PRESS and CV and high values of $\mathrm{R}^{2}$ (e" 0.90$)$. The lack of fit was not significant, which indicated that the number of experimental combinations formed in the design of experiment was enough to find out the effect of independent variables on the brown strength. Acceptable PRESS, CV (less than 10per cent), $\mathrm{R}^{2}$ indicates that the model is sufficient to predict the response. As a general rule, the coefficient of variation should not be greater than 10 per cent. In this case, the coefficient of variation for $\mathrm{T}$ was less than 7 per cent (Table 3 ).

Table 1 independent process variables and their levels for ohmic heating of milk

\begin{tabular}{lllc}
\hline Independent variable & Coded value & & \\
\hline & -1 & 0 & 1 \\
Fat content (per cent) & 3 & 4.5 & 6 \\
Potential difference (V) & 30 & 40 & 50 \\
Inlet Temperature(ÚC) & 30 & 35 & 40 \\
\hline
\end{tabular}

Table 2 Box Behnken design matrix with calculated values of response variables

\begin{tabular}{|c|c|c|c|c|c|c|c|c|c|}
\hline \multirow[t]{3}{*}{ Run } & \multicolumn{7}{|c|}{ Process Variables } & \multirow[b]{3}{*}{$\mathrm{SPC}$} & \multirow[b]{3}{*}{ Capacity } \\
\hline & \multicolumn{4}{|c|}{ Actual values } & \multicolumn{3}{|c|}{ Coded values } & & \\
\hline & Time & Voltage & Inlet temp & $\mathrm{A}$ & $\mathrm{B}$ & $\mathrm{C}$ & $\mathrm{T}\left({ }^{\circ} \mathrm{C}\right)$ & & \\
\hline$\overline{1}$ & 4.5 & 50 & 30 & 0 & 1 & -1 & 73.0 & 52.63 & 32.72 \\
\hline 2 & 4.5 & 50 & 40 & 0 & 1 & 1 & 73.2 & 46.81 & 36.00 \\
\hline 3 & 4.5 & 30 & 30 & 0 & -1 & -1 & 72.5 & 87.97 & 25.71 \\
\hline 4 & 4.5 & 30 & 40 & 0 & -1 & 1 & 72.6 & 78.06 & 30.00 \\
\hline 7 & 3 & 40 & 30 & -1 & 0 & -1 & 72.0 & 58.28 & 28.80 \\
\hline 8 & 3 & 40 & 40 & -1 & 0 & 1 & 72.3 & 48.83 & 30.00 \\
\hline 9 & 6 & 50 & 35 & 1 & 1 & 0 & 74.0 & 58.62 & 40.00 \\
\hline 10 & 6 & 30 & 35 & 1 & -1 & 0 & 73.2 & 90.69 & 30.00 \\
\hline 11 & 3 & 50 & 35 & -1 & 1 & 0 & 72.5 & 43.09 & 32.72 \\
\hline 15 & 4.5 & 40 & 35 & 0 & 0 & 0 & 72.8 & 61.68 & 31.00 \\
\hline 16 & 4.5 & 40 & 35 & 0 & 0 & 0 & 72.9 & 60.05 & 31.20 \\
\hline 17 & 4.5 & 40 & 35 & 0 & 0 & 0 & 72.9 & 60.86 & 31.00 \\
\hline
\end{tabular}


Fig. 2 Response surface showing effect of voltage (B) and fat content (A) on final temperature $(\mathrm{T})$
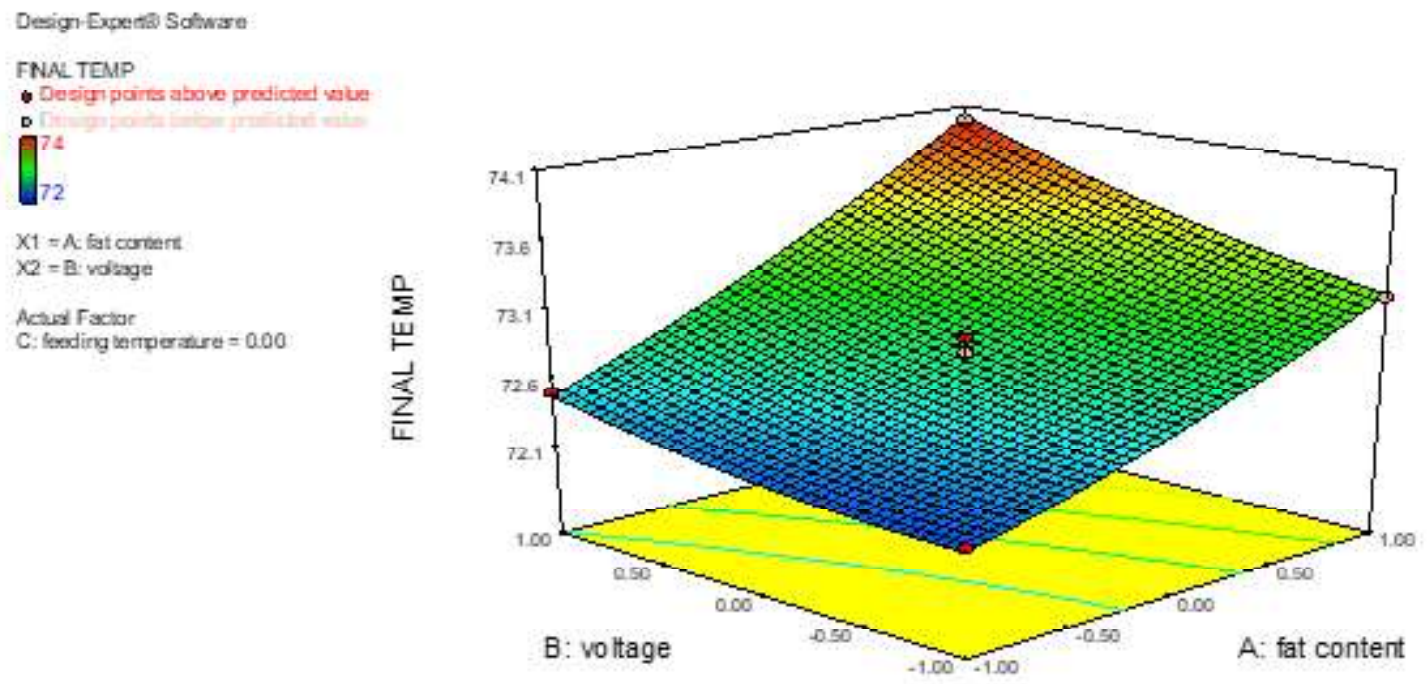

Table 3 Regression coefficients of the second-order polynomial model for the response variables (in coded units)

\begin{tabular}{llll}
\hline Factor & \multicolumn{3}{c}{ Coefficient } \\
\cline { 2 - 4 } & Temperature & SPC & Capacity \\
\hline Constant & 72.82 & 60.70 & 31.3 \\
A-Fat Content & 0.65 & 8.03 & 2.41 \\
B-Voltage & 0.28 & -15.33 & 4.32 \\
C-Feeding Temperature & 0.1 & -5.12 & 1.92 \\
AB & 0.12 & -2.00 & -0.39 \\
AC & -0.02 & -1.58 & 1.35 \\
BC & 0.025 & 1.022 & -0.25 \\
A $^{2}$ & 0.07 & -1.16 & -0.62 \\
B $^{2}$ & 0.07 & 5.34 & 0.29 \\
C $^{2}$ & -0.07 & 0.31 & -0.49 \\
Std. Dev. & 0.074 & 2.70 & 2.07 \\
R & 0.98 & 0.98 & 0.887 \\
C.V. per cent & 0.10 & 4.29 & 6.69 \\
PRESS & 0.20 & 790.63 & 479.66 \\
\hline
\end{tabular}

To visualize the combined effect of the two factors on the response, the response surface and contour plots were generated for each of the models in the function of two independent variables, while keeping the remaining independent variable at the central value (Fig 2).

The feeding temperature (C) having lowest F-value, had least effect on final temperature, $\mathrm{T}$ and therefore was kept fixed along to generate response surface diagram between A and B (fig 2). The figure clearly indicates that final temperature $(T)$ increases with the rise of fat content (A) and voltage (B). An increase in fat content of milk and applied voltage also increases the final temperature of the product.

\section{Effect on Specific Performance Coefficient (SPC)}

The Model F-value of 42.08 implies the model is significant and there is only a 0.01 per cent chance that a "Model F-Value" this large could occur due to noise. The Fisher F-test with a very low probability value ( $\mathrm{P}$ model e" $\mathrm{F}$ at 0.05 ) demonstrates a very high significance for the regression model. Values of "Prob $>$ F" less than 0.0500 indicate model terms are significant. (Table 4)

The overall variation in specific performance coefficient (SPC) was between 43.09 and 90.69 . The minimum specific performance coefficient(SPC) was 43.09 at combination of fat content (A) 3 per cent, applied voltage (B) - $50 \mathrm{~V}$ and feeding temp (C) - 35Ú C.(Table1) However, the maximum specific performance coefficient (SPC) 90.69 was observed at combination of ohmic process fat content (A) -6 per cent, applied voltage (B) $-30 \mathrm{~V}$ and feeding temp $(\mathrm{C})-35$ Ú $\mathrm{C}$. The second order polynomial multiple regression equation for explaining the effect of variation in ohmic process parameters A, B and C on SPC is as follows: 
Fig. 3 Response surface showing effect of voltage (B) And fat content (A) on specific performance coefficient (SPC)

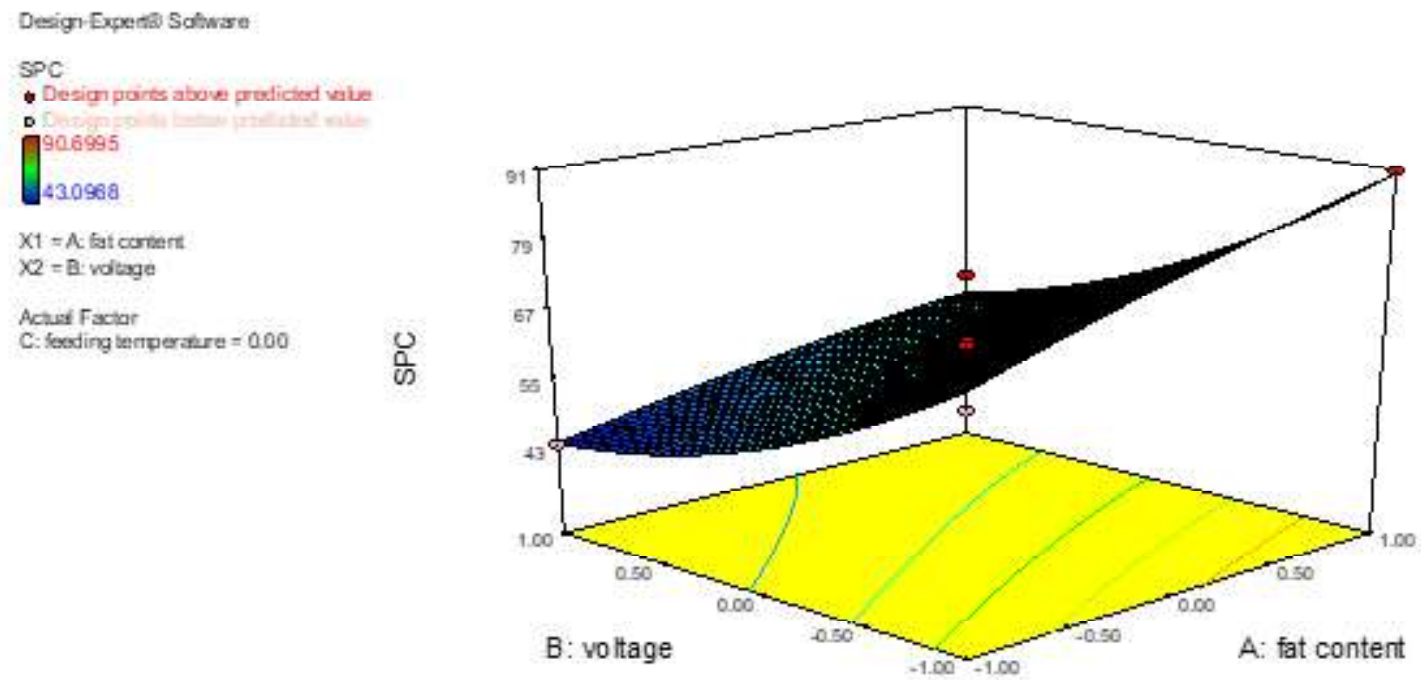

Table 4 ANOVA for effect of independent parameters for response surface quadratic model on temperature (T)

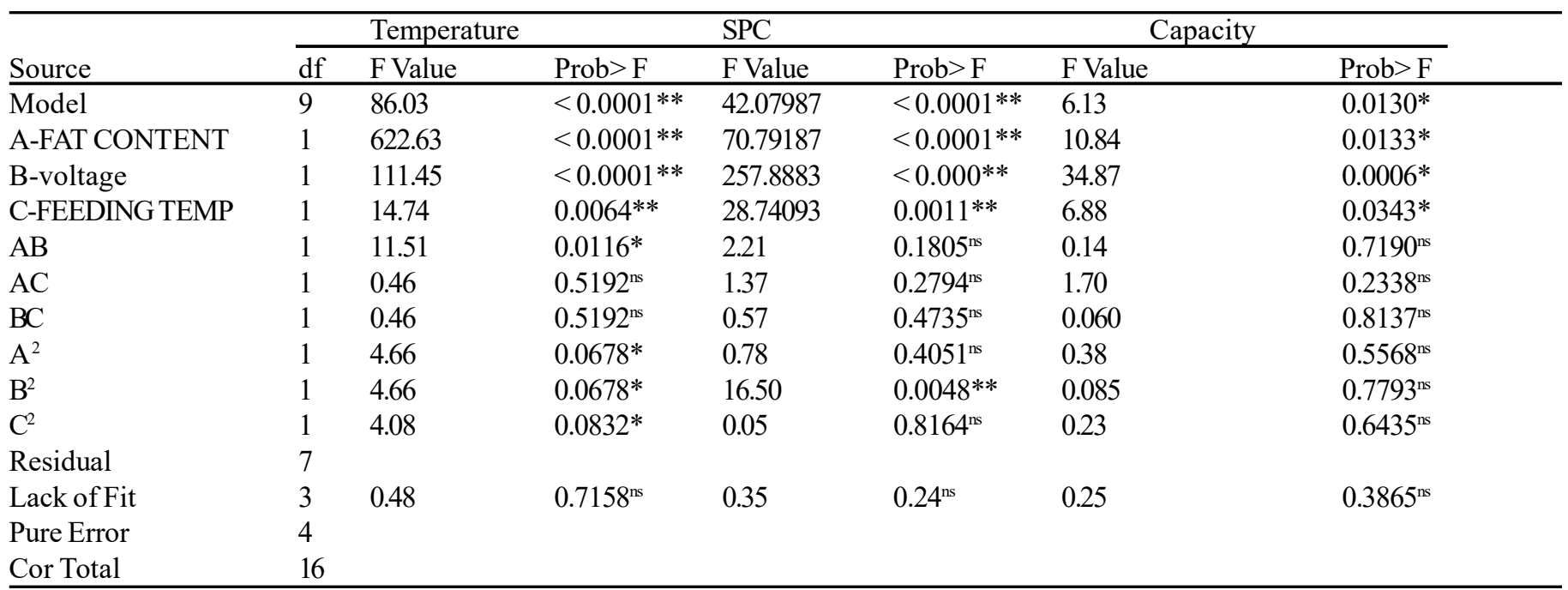

** Highly significant at 1 per cent level, * significant at 5 per cent level, ${ }^{\text {ns }}$ non-significant

$\mathrm{SPC}=60.71+8.04 \mathrm{~A}-15.34 \mathrm{~B}-5.12 \mathrm{C}-2.01 \mathrm{AB}-1.58 \mathrm{AC}+1.02 \mathrm{~B}$

$\mathrm{C}-1.17 \mathrm{~A}^{2}+5.35 \mathrm{~B}^{2}+0.32 \mathrm{C}^{2}$

$\left(\mathrm{R}^{2}\right.$

$=0.9819) \quad \ldots \quad \mathrm{V}$

The relative magnitude of coefficients indicates the negative contribution of linear term of $B$ and $C$; interactive effect of $A B$ and $\mathrm{AC}$ and squared effect of A. Analysis of variance (6.69) indicated that the models are highly significant for all the responses. The lack of fit did not result in a significant value in $\mathrm{A}, \mathrm{B}$ and $\mathrm{C}$ indicating that the models are sufficiently accurate for predicting these responses supported by low value of PRESS and CV and high values of $\mathrm{R}^{2}(\mathrm{e} " 0.80)$. Acceptable PRESS, CV (less than 10per cent), $\mathrm{R}^{2}$ indicates that the model is sufficient to predict the response. The Coefficient of variation was less than 7 per cent.
To visualize the combined effect of the two factors on the response, the response surface and contour plots were generated for each of the models in the function of two independent variables, while keeping the remaining independent variable at the central value (Fig 3). Response surface plots as a function of two factors at a time, maintaining all other factors at fixed levels are more helpful in understanding both the main and the interaction effects of these two factors. These plots can be easily obtained by calculating from the model, the values taken by one factor where the second varies with constraint of a given $Y$ value. The response surface curves were plotted to understand the interaction of the variables and to determine the optimum level of each variable for maximum response.

The feeding temperature (C) having lowest F-value, had least effect on SPC and therefore was kept fixed along to generate response surface diagram between A and B (fig 3). The figure 
Fig. $4 \quad R$ e s p o $n s$ e surface showing effect of voltage (B) and fat content (A) on capacity
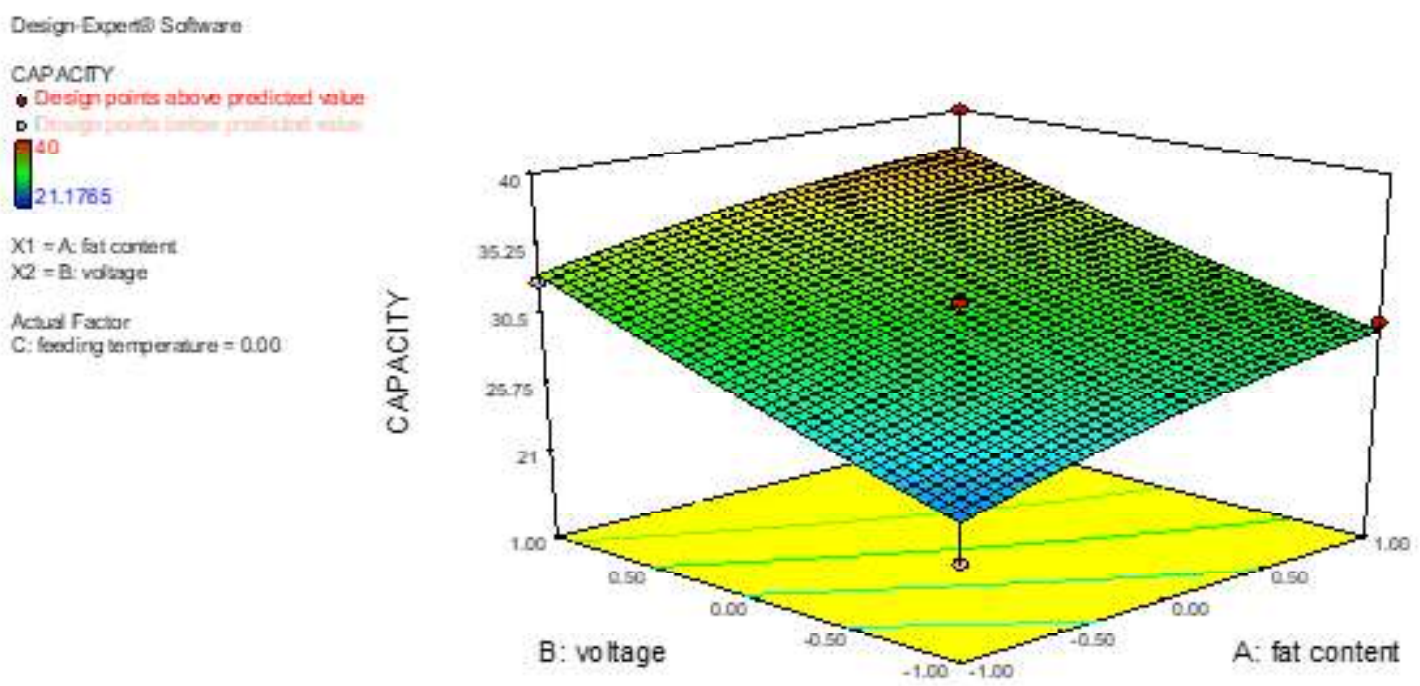

Table 5 Optimum values of process parameters and responses

\begin{tabular}{|c|c|c|c|c|}
\hline Name & Goal & LowerLimit & Upper limit & Importance \\
\hline Fat Content & is in range & -1 & 1 & 3 \\
\hline Voltage & is in range & -1 & 1 & 3 \\
\hline Feeding Temp & is in range & -1 & 1 & 3 \\
\hline Final Temp & is target $=72$ & 72 & 74 & 3 \\
\hline $\mathrm{SPC}$ & maximize & 43.09 & 90.09 & 3 \\
\hline Capacity & maximize & 21.07 & 40 & 3 \\
\hline
\end{tabular}

Table 6 Solution for optimum condition

\begin{tabular}{|c|c|c|c|c|c|c|c|}
\hline Number & fat content & voltage & feeding temp & Final Temp & SPC & Capacity & Desirability \\
\hline$\overline{1}$ & 0.55 & -1 & 1 & 72.92 & 79.89 & 24.13 & 0.753 \\
\hline 2 & 0.54 & -1 & 1 & 72.91 & 79.80 & 24.11 & 0.753 \\
\hline 3 & 0.60 & -1 & 1 & 72.95 & 80.19 & 24.05 & 0.752 \\
\hline
\end{tabular}

clearly indicates increased specific performance coefficient (SPC) changes with the rise A and B. An increase if B will increase SPC while increase in A will increase it.

\section{Effect on capacity}

The Model F-value of 6.13 implies the model is significant. There is only a 1.30 per cent chance that a "Model F-Value" this large could occur due to noise. The Fisher F-test with a very low probability value (P model e" F at 0.05 ) demonstrates a very high significance for the regression model. Values of "Prob $>$ F" less than 0.0500 indicate model terms are significant.

The overall variation in capacity was between 21.17 and 34.28. The minimum capacity was 21.17 observed at combination of fat content (A) - 3per cent, applied voltage (B) - $30 \mathrm{~V}$ and feeding temp (C) 35Ú C. However, the maximum capacity 34.28 was observed at combination of ohmic process fat content (A) - 6per cent, applied voltage (B) - $40 \mathrm{~V}$ and feeding temp (C) $-40^{\circ} \mathrm{C}$.(Table
1) The second order polynomial multiple regression equation for explaining the effect of variation in ohmic process parameters $\mathrm{A}$, $\mathrm{B}$ and $\mathrm{C}$ on capacity is as follows:

$$
\begin{aligned}
& \text { CAPACITY }=31.30+2.41 \mathrm{~A}+4.32 \mathrm{~B}+1.92 \mathrm{C}-0.39 \mathrm{AB}+1.35 \mathrm{AC}- \\
& \begin{array}{c}
0.25 \mathrm{BC}-0.62 \mathrm{~A}^{2}+0.29 \mathrm{~B}^{2}-0.49 \mathrm{C}^{2} \quad\left(\mathrm{R}^{2}=0.8874\right) \\
\text { vi }
\end{array}
\end{aligned}
$$

To visualize the combined effect of the two factors on the response, the response surface and contour plots were generated for each of the models in the function of two independent variables, while keeping the remaining independent variable at the central value (Fig 4). Response surface plots as a function of two factors at a time, maintaining all other factors at fixed levels are more helpful in understanding both the main and the interaction effects of these two factors. These plots can be easily obtained by calculating from the model, the values taken by one factor where the second varies with constraint of a given $Y$ value. The response surface curves were plotted to understand the 
interaction of the variables and to determine the optimum level of each variable for maximum response.

The feeding temp (C) having lowest F-value, had least effect on capacity and therefore was kept fixed along to generate response surface diagram between fat content (A) and applied voltage (B) (fig 4). The figure clearly indicates increased capacity changes with the rise in fat content (A) and applied voltage (B). An increase in applied voltage (B) will increase capacity while increase in fat content (A) will also increase it.

\section{Optimization of ohmic heating}

In order to optimize the process conditions during ohmic heating, the considerations were: (1) Target value of final temperature as $72^{\circ} \mathrm{C}$ and (2) Maximization of system performance coefficient and (3) Maximizing capacity. Optimization was carried out with the help of commercial statistical package (Design Expert, Version 7.0, State Ease Inc., Minneapolis, IN statistical software), (Table $6)$. The optimum solution from this package was emerged out as fat content $(\mathrm{A})-5$ per cent, applied voltage $(\mathrm{B})-30 \mathrm{~V}$ and feeding temp $(\mathrm{C})-40^{\circ} \mathrm{C}$ in order to obtain optimized yield as final temperature $(\mathrm{T})-72^{\circ} \mathrm{C}$; and specific performance coefficient (SPC)-79.8 and capacity of $25 \mathrm{lph}$ with desirability of 0.753 .

The value of fat content at 0.55 represents 5 per cent of fat content and the value of voltage at -1 represents $30 \mathrm{~V}$ and similarly the value of feeding temperature at 1 represents 40, and these combinations were optimum for corrosponding value for targeted final temperature of 72, specific performance coefficient of 79.89 per cent and for the capacity of $24 l p h$ in order to provide a desirabilty of 0.753 (Table 6).

\section{Conclusions}

Response surface analysis was effectively used to determine the effect of fat content, applied voltage and inlet temperature during ohmic heating of milk for pasteurization. Ohmic heating experiments were conducted employing Box-Bohenken Design for three independent variables with three levels each (fat content - 3, 4.5, 6 per cent; Applied voltage $-30,40,50 \mathrm{~V}$; feeding temperature $-30,35,40^{\circ} \mathrm{C}$ ). The optimum solution from this package was emerged out as ohmic fat content -5 per cent, applied voltage $-30 \mathrm{~V}$ and feeding temperature $-40^{\circ} \mathrm{C}$ in order to obtain optimized yield as final temperature $-72^{\circ} \mathrm{C}$; spc of 79.8 and capacity of $25 \mathrm{lph}$ with desirability of 0.753 .

\section{References}

Ayadi MA, Leulie JC, Chopard F, Berthou M, Lebouche M (2005) Experimental study of hydrodynamics in a flat ohmiccell impact on fouling by dairy products. Journal of Food Engineering 70: 489-498

Bansal B and Chen XD (2006) Effect of temperature and power frequency on milk fouling in an ohmic heater. Food and Bioproducts Processing 84(C4): 286-291
Castro I, Bozkurt H, Bayer T (2004) The effect of electric field on important food processing enzymes: comparison of inactivation kinetics under conventional and ohmic heating. Journal of Food Science 69(9): 696-701

Cho HY, Yousef, AE, Sastry SK (1996) Growth kinetics of Lactobacillus acidophilus under ohmic heating. Biotechnology and Bioengineer 49(3): 334-340

Fellows P 2000, Food Processing Technology. Principles and Practice, 2nd edition, Boca Raton, FL, CRC Press

Ghnimi S, Flach-Malaspina N, Dresch M, Delaplace G. and Maingonnat JF (2008) Design and performance evaluation of an ohmic heating unit for thermal processing of highly viscous liquids. Chemical Engineering Research and Design 86(6): 626-632

Halden K, De Alwis AAP, Fryer PJ (1990) Changes in the electrical conductivity of foods during ohmic heating. International Journal of Food Science \& Technology 25(1) :9-25

Huixian SUN, Kawamura S, Himoto, JI, Tatsuhiko WADA, Kimura T (2008) Effects of ohmic heating on microbial counts and denaturation of proteins in milk. Food science and technology research 14(2): 117-123

Icier F and Ilicali C (2005) The use of tylose as a food analog in ohmic heating studies. Journal of Food Engineering, 69(1): 67-77.

Kim HJ, Choi YM, Yang APP, Yang TCS, Taub IA, Giles J, Ditusa C, Chall S, Zoltal P (1996) Microbiological and chemical investigation of ohmic heating of particulate foods using a $5 \mathrm{~kW}$ ohmic system. Journal of Food Processing and Preservation 20: 41-58

Lima M, Sastry SK (1999) The effects of ohmic heating frequency on hot air drying rate and juice yield. Journal of Food Engineering 41: 115-119

Leizerson S and Shimoni E 2005.Stability and Sensory Shelf Life of Orange Juice Pasteurized by Continuous Ohmic Heating. Journal of Agricultural and Food Chemistry 53(10): 4012-4018

Marra F, Zell M, Lyng JG, Morgan DJ, \& Cronin D.A. 2009. Analysis of heattransfer

during ohmic processing of a solid food. Journal of Food Engineering 91: $56-63$

Palaniappan S, Richter ER and Sastry SK 1990. Effects of electricity on microorganisms: A review. Journal of Food Process Preservation 14: 393-414

Phirke PS (2014) Processing equipment and design, Jain Brothers, New Delhi

Ramaswamy HS, Marcotte M, Sastry S, Abdelrahim K (2010) Ohmic heating in food processing CRC Press, Taylor \& Francis Group, New York

Roux S, Courel M, Picart-Palmade L, Pierre JP (2010) Design of an ohmic heater to study the kinetics of thermal reactions in liquid products. Journal of Food Engineering 98: 398-407

Ruan R, Ye X, Chen P, Doona CJ (2001) Ohmic heating. In P. Richardson Thermal technologies in food processing (pp. 165-241). Cambridge: Woodhead Publishing Limited

Ruan R, Ye X, Chen P, Doona C, Yang T (2004) Developments in ohmic heating. Improving the thermal processing of foods, pp.224-252

Saini A, Kumar R (2015) Construction of an ohmic heating apparatus and evaluation of Electrical conductivity of sweet lime juice. International Journal for Research in Applied Science and Engineering Technology 3:

Salengke S, Sastry SK 2007.Models for ohmic heating of solid-liquid mixtures under worst-case heating scenarios. Journal of Food Engineering 83: 337-355

Sarkis JR, Mercali GD, Tessaro, IC Marczak LDF 2013. Evaluation of key parameters during construction and operation of an ohmic heating apparatus. Innovative Food Science and Emerging Technologies 18:145-149 
Sastry SK, Li Q (1996) Modelling the ohmic heating of foods. Food Technology 50(5):246-248

Sastry SK, Yousef A, Cho HY, Unal R, Salengke S, Wang WC, Lima M, Kulshrestha S, Wongsa-Ngasri P, Sensoy I (2002) Ohmic heating and moderate electric field (MEF) processing', in Welti-Chanes J, Barbosa-CaÂnovas GV and Aguilera JM, Engineering and Food for the 21st Century, Boca Raton FL, CRC Press.154

Sinthiya R (2015) Design and fabrication of ohmic heating equipment. Food Science and Quality management 35:

Stancl J, Zitny R (2010) Milk Fouling at Direct Ohmic Heating. Journal of Food Engineering 99(4):437-444

Tham HJ, Chen XD, Brent R, Duffy G (2009) Ohmic heating of dairy fluids - effects of local electric field on temperature distribution. Asia-Pacific Journal of Chemical Engineering 4: 751-758

Vicente AA, Castro I, Teixeira JA (2006) Innovations in thermal food processes. In Da-Wen Sun (Ed.), Thermal food processing: New technologies and quality issues (pp. 424 -468). Boca Raton, FL, USA: CRC Press, Taylor \& Francis Group

Wang WC, Sastry SK (1993) Salt diffusion into vegetable tissue as a pretreatment for ohmic heating: electrical conductivity profiles and vacuum infusion studies', Journal of Food Engineering 20: 299309.

Zell M, Lyng JG, Morgan DJ and Cronin DA 2009. Development of rapid response thermocouple probes for use in a batch ohmic heating system. Journal of Food Engineering 93: 344-347

Zareifard, MR, Ramaswamy HS, Trigui M, Marcotte M (2003) Ohmic heating behaviour and electrical conductivity of two-phase food systems. Innovative Food Science and Emerging Technologies 4: $45-55$ 